\title{
What is meant by "frailty" in undergraduate medical education? A national survey of UK medical schools
}

\author{
Rebecca Winter $^{1}$ (D) Muna Al-Jawad ${ }^{1} \cdot$ Juliet Wright $^{1} \cdot$ Duncan Shrewsbury $^{2} \cdot$ Harm Van Marwijk $^{2} \cdot$ Helen Johnson $^{3}$. \\ Tom Levett ${ }^{4}$
}

Received: 9 December 2020 / Accepted: 2 February 2021 / Published online: 2 March 2021

(c) The Author(s) 2021

\section{Key summary points}

Aim UK medical schools are required to teach about frailty but the term is open to interpretation. This national survey aims to understand how frailty has been perceived and approached by schools.

Findings Frailty is perceived and approached in a broad variety of ways ranging from a long term condition to geriatric medicine in its entirety. A range of educational approaches have been used to teach and assess, with little constructive alignment to match learning outcomes. Teaching is most commonly opportunistic, by a student observing geriatric ward rounds. Message Frailty is open to individual interpretation. Expert consensus should be reached regarding the core areas to include in UGME around the topic of frailty. It would be prudent to explore which frailty-related educational strategies enhance student knowledge, attitudes and values towards frailty.

\begin{abstract}
Purpose All UK medical schools are required to include frailty in their curriculum. The term is open to interpretation and associated with negative perceptions. Understanding and recognising frailty is a prerequisite for consideration of frailty in the treatment decision-making process across clinical specialities. The aim of this survey was to describe how frailty has been interpreted and approached in UK undergraduate medical education and provide examples of educational strategies employed. Methods All UK medical schools were invited to complete an electronic survey. Schools described educational strategies used to teach and assess frailty and provided frailty-related learning outcomes. Learning Outcomes were grouped into categories and mapped to the domains of Outcomes for Graduates (knowledge, skills and values).

Results 25/34 Medical schools (74\%) participated. The interpretation of what frailty is vary widely and the diversity of teaching strategies reflect this. The most common Learning outcomes included as "Frailty" are about the concept of frailty, Comprehensive Geriatric Assessments and Roles of the MDT. Frailty teaching is predominantly opportunistic and occurred within geriatric medicine rotations in all medical schools. Assessments focus on frailty syndromes such as falls and delirium. Conclusion There is variation regarding how frailty has been interpreted and approached by medical schools. Frailty is represented in an array of teaching and assessment methods, with a lack of constructive alignment to related learning outcomes.
\end{abstract}

Rebecca Winter

r.winter2@bsms.ac.uk

1 Department of Medical Education, Brighton and Sussex Medical School, Room 344A Mayfield House, Falmer, Brighton BN1 9PH, UK

2 Department of Primary Care and Public Health, Brighton and Sussex Medical School, Brighton BN1 9PH, UK

3 School of Applied Social Science, University of Brighton, Brighton BN1 9PH, UK

4 Department of Clinical and Experimental Medicine Brighton, Brighton BN1 9PH, UK 
Consensus should be agreed as to what frailty means in medical education. Further research is required to explore which frailty-specific educational strategies in undergraduate medical education enhance learning.

Keywords Frailty $\cdot$ Teaching $\cdot$ Assessment $\cdot$ Medical education $\cdot$ Undergraduate $\cdot$ Curriculum

\section{Introduction}

People living with frailty account for $20 \%$ of hospital inpatients and half of all hospital bed days in the UK [1]. Medical students will encounter many patients with frailty, across a breadth of clinical specialities and clinical conditions, which requires an in-depth understanding of frailty. The understanding and recognition of frailty is a prerequisite for consideration of frailty in the treatment decision-making process [2]. The 2018 General Medical Council (GMC) Outcomes for Graduates (OfG) document reflects this, with a requirement that medical schools include frailty in their curriculum [3].

The challenges associated with teaching and learning about frailty include negative perceptions, lack of a universal definition and variation in the interpretation among healthcare professionals [4-7]. There is minimal evidence around medical students' perception and understanding of frailty. Nimmons et al. found that medical students do not recognise the concept of frailty [8], whilst Mccarthy et al. found that students consider ageing and frailty differently, with frailty attracting more negative associations [9]. A systematic review in postgraduate education found no relevant publications addressed the evidence of educational programmes for frailty prevention and/or frailty management [10]. This gap in training of healthcare professionals has been highlighted as a main barrier towards identifying and managing frailty [11]. There is some evidence to suggest that with teaching the perceived importance and competence in assessing, diagnosing and managing frailty can improve [12].

The aim of this national survey is to outline the interpretation and approach to frailty in Undergraduate Medical Education (UGME) in UK medical schools, to provide a cross section of current practice and describe planned changes to meet the OfG recommendations [3].

\section{Method}

The Brighton and Sussex Medical School (BSMS) Research Governance and Ethics Committee (RGEC) granted ethical approval to proceed with this project in December 2018. (Reference: ER/BSMS9638/1).

The survey was generated using Qualtrics software [13], an electronic survey tool. Questions were designed by consensus, based on the British Geriatric Society (BGS) Good Practice Guide for Frailty [14], national frailty guidance [15] and similar national surveys [16-19]. The survey was piloted by senior members of faculty at one UK medical school, adapted following feedback and reviewed and endorsed for circulation by the BGS Education and Training Committee. The survey included open and closed questions, with free text boxes to expand on responses. Schools were asked to provide frailty-related learning outcomes (LOs). All respondents were invited for a follow up telephone call to clarify and expand on responses.

The medical education leads (MELs) from 34 UK medical schools were contacted through the Medical School Council. The MELs nominated a representative with knowledge of frailty in their undergraduate medical curriculum. Three routine reminders were sent. Non-responding schools were then contacted once by education representatives from the BGS Trainees Council.

Data were collected over 6 months. Medical schools were anonymised and randomly assigned a code between M1 and M25. Responses from the survey and telephone follow up were analysed using descriptive statistics and descriptive content analysis; a systematic approach used for exploring large amounts of textual information to describe the characteristics of the document's content [20]. To demonstrate the variety of content included under the term frailty, the frailtyrelated LOs were grouped into categories by three authors (RW, MAJ, TL). These authors collectively mapped each LO to a domain within OfG (knowledge, skills or values).

\section{Results}

Responses were received from $74 \%$ (25/34) of medical schools. $56 \%$ of respondents (14/25) participated in follow up telephone calls. 92\% (23/25) of respondents held both clinical and academic roles. Of these, $70 \%(16 / 23)$ were the lead of geriatric medicine (GM) modules and 87\% (20/23) were consultant geriatricians.

\section{Teaching about frailty}

Frailty is taught in $80 \%(20 / 25)$ of responding schools. Where frailty is taught, $100 \%(20 / 20)$ indicated that frailty teaching occurred within GM modules; exclusively so in $50 \%$. Geriatricians contribute to frailty teaching in all cases alongside other professionals. However, in $20 \%$ of cases, only geriatricians deliver frailty teaching. $80 \%$ of schools described combinations of multidisciplinary team (MDT) 
members as faculty, with a minimum of three disciplines (for example geriatrician, occupational therapist, physiotherapist). In 25\% of schools, General Practitioners deliver teaching on frailty.

The content of frailty teaching includes: the definition of frailty (100\%); frailty screening and assessment tools (95\%); roles of the MDT in frailty care $(95 \%)$; frailty diagnosis (90\%); and frailty management (90\%). 55\% of schools taught about frailty prevention. 25\% described that students learn about frailty through completing or observing the Clinical Frailty Scale (CFS): "Students encounter frailty in the form of the clinical frailty scale being done on all patients when they come into hospital". (M7).

Most medical schools (95\%) perceive that frailty teaching occurs opportunistically on clinical placement: "Students should get some exposure to clinical geriatrics during medical ward attachments and this will include patients with frailty" (M25) and "Frailty [is] not formally, specifically delivered to all however likely to crop up..." (M7). Of formal teaching, $85 \%(17 / 20)$ teach about frailty via case studies, typically based around patients presenting with a fall, delirium or a chronic condition such as heart failure. $80 \%$ use small group teaching and $80 \%$ use lectures. $45 \%$ teach via community visits. Only $30 \%$ of medical schools use computer aided learning to teach about frailty. Four examples of teaching are summarised in Table 1, reflecting the diversity of approaches.

In $65 \%$ of cases, frailty is taught in 2 year groups, most commonly years 2 and 4 although several combinations of a junior year (years 1,2$)$ and senior years $(3,4,5,6)$ were provided. Year 4 receives frailty teaching in $65 \%$ of medical schools and were the year group most commonly assessed on frailty (75\%). $20 \%$ of medical schools teach frailty with students from other professions. These include prescribing workshops in two medical schools, with medical students, pharmacy students and nursing students. Other interprofessional education (IPE) sessions included teaching around ethical issues in ageing and frailty, and a seminar about discharge planning.

\section{Learning outcomes}

$60 \%(12 / 20)$ Of schools provided LOs relevant to frailty, demonstrating a variation in how frailty has been interpreted by schools. Sixty-one learning outcomes were received and grouped into fourteen categories (Table 2). LOs were mapped to the domains in the OfG document; thirteen LOs covered more than one domain. Knowledge was represented most commonly (40/61); followed by values (18/61) and skills (16/61). Only $17 \%$ (2/12) of medical schools provided LOs spanning all three domains.

\section{Assessments on frailty}

Most schools (90\%, 18/20) assess frailty. One school reported teaching without assessments about frailty and another assesses frailty without teaching.

A variety of formal assessment methods relating to frailty were described. Objective Structured Clinical Exams (OSCE's) (85\%) and Single Best Answer (SBA) (70\%) were the most common formative methods used. Examples provided include questions around older patients presenting with frailty syndromes (namely falls and delirium) rather than specific questions about frailty. Case discussion (45\%), reflective writing (30\%) and Short Answer Questions (25\%) were also used. Summative assessments including logbook completion and Workplace Based Assessments were common.

Table 1 Examples of teaching in practice

\begin{tabular}{|c|c|}
\hline Modality & Content \\
\hline $\begin{array}{l}\text { Pre-reading of two seminal papers on frailty } \\
\text { and sarcopenia [41, 42] } \\
\text { Completion of a case-based workbook } \\
\text { Online learning module } \\
\text { Small group discussion } \\
\text { Clinical skill sessions }\end{array}$ & $\begin{array}{l}\text { Based around a patient with heart failure who has frailty. Students need to complete a work- } \\
\text { book and decide the patient's frailty status based on the phenotype and cumulative deficit } \\
\text { models. CGA is taught by a variety of modalities and faculty and clinical skills sessions on } \\
\text { gait and balance assessment is delivered by physiotherapists. (M23) }\end{array}$ \\
\hline A frailty teaching ward round (WR) & $\begin{array}{l}\text { Led by a Teaching Fellow (TF), within and parallel to the consultant WR. The TF identifies } \\
\text { and highlights key learning opportunities to the students. Students are taken aside for a short } \\
\text { tutorial led by the TF, running parallel to the WR, to discuss a topic in more depth, to help } \\
\text { break down the complexity and uncertainty surrounding frail patients. (M3) }\end{array}$ \\
\hline $\begin{array}{l}\text { Online tutorial and video } \\
\text { Small group discussion }\end{array}$ & $\begin{array}{l}\text { Introduce normal ageing and then frailty, including watching 'Mrs Andrews' story' [43]. } \\
\text { Important learning points are discussed in small groups around a clinical case. (M11) }\end{array}$ \\
\hline $\begin{array}{l}\text { Year-long longitudinal primary care placement } \\
\text { Reflective writing }\end{array}$ & $\begin{array}{l}\text { Students attend placement weekly with a specific focus on patients with frailty. They complete } \\
\text { a CGA and management plan on a patient they have seen } \\
\text { Students undertake a three-part reflective written piece on the meaning of frailty from the per- } \\
\text { spectives of the patient, MDT and student, bringing in a critical evaluation of their manage- } \\
\text { ment plan and the literature around frailty. }(M 10)\end{array}$ \\
\hline
\end{tabular}


Table 2 Frailty learning outcomes and their categories

\begin{tabular}{|c|c|c|}
\hline Category & Example learning outcome & $\begin{array}{l}\text { Proportion of } \\
\text { LOs in each } \\
\text { category }\end{array}$ \\
\hline The concept of frailty & Understand and describe the concept of frailty $(M 4)$ & $8 / 61$ \\
\hline CGA & $\begin{array}{l}\text { Understand what comprehensive geriatric assessment is, its importance; be } \\
\text { aware of the evidence supporting this approach in improving health out- } \\
\text { comes in frail older people. (M17) }\end{array}$ & $8 / 61$ \\
\hline MDT roles, and discharge planning & $\begin{array}{l}\text { Recognition of the need to work constructively and considerately with other } \\
\text { members of the MDT, family and carers (M3) }\end{array}$ & $7 / 61$ \\
\hline Impact of illness on the older adult & $\begin{array}{l}\text { Recognise that ill health in older people is often due to a complex mix of } \\
\text { medical, physical, psychological, and social problems. (M15) }\end{array}$ & $6 / 61$ \\
\hline Social impact of ageing & $\begin{array}{l}\text { Consider the burden imposed on the healthcare system by an increasing } \\
\text { aging population and what strategies might be employed to manage this } \\
\text { (M1O) }\end{array}$ & $4 / 61$ \\
\hline Polypharmacy in an older adult & $\begin{array}{l}\text { Recognise drug actions, therapeutics, pharmacokinetics, drug side effects, } \\
\text { the effects of polypharmacy, the principles of safe drug prescription in the } \\
\text { older person (M11) }\end{array}$ & $4 / 61$ \\
\hline Chronic conditions in the older person & $\begin{array}{l}\text { Understand the basic principles and options / strategies for "Chronic Disease } \\
\text { Management" in the Older Patient. For e.g. CCF; COPD; Dementia; } \\
\text { Chronic Leg Ulcers with reduced Mobility; Osteoporotic fractures; Cer- } \\
\text { ebrovascular Disease; Parkinson's (M2) }\end{array}$ & $4 / 61$ \\
\hline Ethical and legal topics around the older patient & $\begin{array}{l}\text { Assess patient's capacity in accordance with legal requirements and GMC } \\
\text { guidance. This includes the Mental Capacity Act 2005, Deprivation of } \\
\text { Liberties Safeguards (DoLS) and the role of Best Interest Decisions (M11) }\end{array}$ & $3 / 61$ \\
\hline ACP, EOL Care and Death & $\begin{array}{l}\text { Understand the basic principles of "Realistic Medicine," "Advance Care } \\
\text { Planning," "Anticipatory Care Planning," "End of Life Care" / Palliative } \\
\text { Care (especially in relation to Older Patients) (M2) }\end{array}$ & $3 / 61$ \\
\hline Frailty scores & Describe some common frailty scores. $(M 1)$ & $3 / 61$ \\
\hline Frailty syndromes & To describe frailty syndromes in context of Isaac's Geriatric Giants (M25) & $3 / 61$ \\
\hline Investigations & $\begin{array}{l}\text { Initiate, justify and interpret appropriate haematological, biochemical, } \\
\text { radiological and other relevant investigations pertaining to the clinical } \\
\text { condition(s) (M11) }\end{array}$ & $3 / 61$ \\
\hline Multimorbidity and disability & $\begin{array}{l}\text { Assess the functional ability of a patient, relating function and disability to } \\
\text { the underlying disease process }(M 10)\end{array}$ & $3 / 61$ \\
\hline Gerontology & $\begin{array}{l}\text { To develop an understanding of the biology of Ageing and the factors that } \\
\text { can promote/ lead to healthy ageing (M4) }\end{array}$ & $2 / 61$ \\
\hline
\end{tabular}

\section{Planned GMC changes}

$60 \%$ of medical schools (15/25) have planned changes to meet the OfG recommendations surrounding frailty. One medical school plans to evolve their programme to include more frailty based on the BGS undergraduate curricula; [21] three schools are extending the time allocated in primary care placements to deliver frailty teaching in the community, although it is unclear what this means in practice. All schools that do not teach or assess frailty are planning curriculum changes.

\section{Discussion}

The survey provides the first analysis of teaching and assessment of frailty in UGME; exploring how frailty has been interpreted and approached by UK medical schools through descriptions, examples and LOs. The majority of schools identified that frailty is being taught and assessed in their institution yet there is significant variation in perception of what frailty is and how frailty teaching has been interpreted by medical schools. Frailty is taught using an array of educational approaches ranging from opportunistic teaching on ward rounds to small group learning to reflective writing. There appeared to be little consensus as to which aspects about frailty should be considered core in UGME but within the LOs provided, the concept of frailty, CGA and the roles of the MDT featured most commonly.

Some of the provided LOs represented frailty as a longterm condition within GM (the concept of frailty, frailty assessment tools such as the Clinical Frailty Scale) and others considered frailty to equate to the whole of GM (chronic conditions in the older patient, social impact of ageing, gerontology). This reflects ongoing discussion amongst 
academics and clinical educators [22], yet in terms of education frailty is currently mentioned within both the British and European Undergraduate Curriculum in GM as opposed to representing the GM curriculum in its entirety: "Discuss the generalisability of existing research studies to frail older people..." [21] and "Define the concept of frailty in older people" [23]. A curricular update including the position of these influential bodies of how frailty is best situated in UGME is required.

Of the LOs provided, knowledge about frailty was the OfG domain represented most commonly. Only two schools provided LOs spanning all three OfG domains. OfG now discusses the domain of values, not attitudes but our findings mirror previous surveys describing UK undergraduate teaching on delirium and dementia, which also identified failure to address student attitudes [18, 19]. Whilst medical students' attitudes towards older patients are acknowledged $[24,25]$, little is known regarding medical students' attitudes towards patients with frailty. A qualitative study found that fourth year medical students did not recognise frailty as a medical entity or demonstrate an understanding of management principles [8]. Another study of UK medical students found that students consider ageing and frailty as different concepts, with frailty attracting more negative associations [9].

Frailty teaching was widely delivered through ward rounds and clinical placements, commonly opportunistically. Simply being present in a clinical environment, however, does not guarantee that students will recognise or understand the concept of frailty. Furthermore, the nature of frailty means that people often present in an atypical manner, with multiple comorbidities and changes in functional ability, which can be challenging even for experts. Many schools use a systems-based approach to learning. Given that frailty is a multi-system condition, it is unclear of the optimal stage in undergraduate training to introduce teaching and assessment about frailty.

A number of schools discussed that students learn about frailty by completing or observing the CFS [26]. The CFS was designed to enable frailty to be measured in the outpatient clinical setting, not to teach about frailty [15]. It is often completed by the most junior member of the team, when a patient is acutely unwell. As an opportunistic teaching tool, the visual scale may over-simplify frailty when trying to teach the complexity and nuance of frailty.

Patients are currently included in frailty teaching opportunistically in the clinical environment. This is a missed opportunity as it is recognised that patient-educators have a significant role in supporting students' learning. Their personal insights could be crucial as there are known negative perceptions towards frailty among older persons [5, 27].

There is a wealth of data regarding the relevance of frailty on patient outcome in clinical specialties other than geriatric medicine [28-31]. However, this survey suggests that currently geriatricians hold the responsibility for delivering frailty teaching in UGME. It also suggests that the gatekeeper, in this case a senior member of medical school faculty, perceives that frailty is the responsibility of GM. The extent of this positioning on what students learn about frailty is unclear. The concern is that restricting frailty to GM rotations may be too reductive as students must be aware that patients they encounter on nongeriatric placements have frailty, and appreciate that the same principles of presentation and management apply.

Only a small proportion of medical schools currently teach about frailty in the community. It is compulsory for foundation doctors to undertake a community placement and is a key recommendation for medical students in OfG $[3,32,33]$. Furthermore, there is an increasingly recognised role of primary care in identifying and managing frailty; in 2017 NHS England introduced a new requirement for all general practices to identify and appropriately manage all patients over the age of sixty-five with moderate or severe frailty $[34,35]$.The most commonly reported medical school change to meet OfG included increasing time that students spend in primary care.

A multi-disciplinary approach is required to meet the complex care needs of older people living with frailty [15]. 80\% of medical schools use at least 3 members of the MDT to teach about frailty. Conversely, the proportion of schools framing interprofessional education (IPE) around frailty was low at 20\%. IPE occurs when students from two or more professions learn about, from and with each other to improve health outcomes. It has been shown to be effective in positively changing patient outcomes in the topics of delirium, dementia and falls [36-38] and is advocated in OfG [3].

The assessment examples and descriptions most commonly described OSCE scenarios, including a history or communication station involving a frailty syndrome (fall, episode of delirium) or prescribing stations demonstrating polypharmacy. The examples do not appear to reflect the LOs provided, nor the diversity of the teaching that has been described. For example, all medical schools teach the definition and diagnosis of frailty, yet none assess this. This reflects a lack of constructive alignment; where all components in the educational system including the LOs, teaching methods and assessment methods should align to each other [39]. Assessment has been shown to drive learning and there is a significant link between the weighting of a subject within an assessment scheme and medical students' reported motivation towards learning the subject [40]. The Medical Licencing Assessment (MLA) is a national examination, based on the blueprint of OfG and will commence in 2023 [3]. Consensus should be reached prior to the commencement of the exam of how frailty will be best assessed. 
A strength of this study is the high response rate for a survey of this type, capturing a breadth of experiences, with participation maximised through a number of recruitment measures. The survey has some limitations. Not all UK medical schools were represented and data were collected from one individual at each medical school. This may introduce bias due to their knowledge of their curriculum. It can be challenging to assess individual performance; a person with greater knowledge about frailty may paradoxically be more likely to evaluate themselves poorly. In this survey two schools that identified they did not teach about frailty showed an insightful understanding of frailty. Lastly, the integrated nature of frailty across multiple conditions and body systems alongside the nature of some medical schools' curricula meant that the structure of a survey may have made it more difficult for schools to detail responses and extract frailty-related LOs. However, to align with the OfG document, medical schools will need to be able to map frailty to their curriculum.

We acknowledge this survey focusses on the UK picture only. The literature surrounding frailty-specific teaching and learning is currently restricted to the UK and Australia [8, $9,12]$. Owing to the presence of frailty-related learning outcomes in the European Medical Undergraduate Curriculum [23], replicating the survey within Europe would provide a broader picture and share areas of good practice.

We recommend that expert consensus should be reached regarding the core areas to include in UGME around the topic of frailty. This should be included in future versions of the undergraduate curriculum produced by learned societies such as the BGS and the European Geriatric Society. In view of the variation in frailty-related educational strategies, it would be prudent to explore which strategies enhance student learning around frailty. Medical schools should ensure that frailty-related LOs are taught and assessed to follow the principles of constructive alignment. Furthermore, there should be careful consideration as to how frailty assessments feature within the national MLA. Further research is required to understand how medical students and clinical teachers across specialties perceive frailty, how these perceptions impact what students learn in the clinical environment, and how frailty being positioned within geriatric medicine impacts on student learning.

In summary, frailty is complex, open to interpretation and negatively perceived. This is the first survey to explore frailty in UGME and describes the how frailty has been interpreted and approached in diverse ways in UK curricula. Recommendations are provided to lead the way in preparing tomorrows doctors for the patients of the future.

Acknowledgements We would like to acknowledge the support from the Medical Schools Council and British Geriatric Society Education and Training Committee and Trainee Representatives, especially Clare
Owen, Dr Robert Wears, Dr Stephen Lim, Dr Tina Ryan and Dr Lauren McCluskey. Many thanks go out to all the medical schools that took to time to participate in the survey.

Author contributions RW, supported by the other authors, was responsible for the overall design, analysis and completion of the survey. JW, DS, HvM, TL piloted the survey and offered feedback. RW, MAJ and TL analysed the data. All authors were involved with study design and have reviewed the manuscript at various stages.

Funding No funding has been received.

Data availability Available on request to main author.

\section{Compliance with ethical standards}

Conflict of interest The authors report no conflict of interest.

Ethical approval The Brighton and Sussex Medical School (BSMS) Research Governance and Ethics Committee (RGEC) granted ethical approval to proceed with this project in December2018. (Reference: ER/BSMS9638/1).

Informed consent Informed consent was obtained from all individual participants included in the study.

Open Access This article is licensed under a Creative Commons Attribution 4.0 International License, which permits use, sharing, adaptation, distribution and reproduction in any medium or format, as long as you give appropriate credit to the original author(s) and the source, provide a link to the Creative Commons licence, and indicate if changes were made. The images or other third party material in this article are included in the article's Creative Commons licence, unless indicated otherwise in a credit line to the material. If material is not included in the article's Creative Commons licence and your intended use is not permitted by statutory regulation or exceeds the permitted use, you will need to obtain permission directly from the copyright holder. To view a copy of this licence, visit http://creativecommons.org/licenses/by/4.0/.

\section{References}

1. Gilbert T, Neuburger J, Kraindler J, Keeble E, Smith P, Ariti C (2018) Development and validation of a Hospital Frailty Risk Score focusing on older people in acute care settings using electronic hospital records: an observational study. Lancet 391:1775-1782

2. Liau SJ, Lalic S, Sluggett JK, Cesari M, Onder G, Vetrano DL (2021) Medication management in frail older people: consensus principles for clinical practice, research, and education. J Am Med Dir Assoc 22(1):43-49

3. GMC. Outcomes for Graduates. 2018. Available from: https:// www.gmc-uk.org/-/media/documents/dc11326-outcomes-forgraduates-2018_pdf-75040796.pdf, Accessed 15 Jan 2020

4. Junius-Walker U, Onder G, Soleymani D, Wiese B, Albaina O, Bernabei R (2018) The essence of frailty: a systematic review and qualitative synthesis on frailty concepts and definitions. Eur J Intern Med 56:1-8

5. Britain Thinks. Frailty: Language and perceptions a report prepared by britain thinks on behalf of Age UK and the British Geriatrics Society. 2015. Available from: http://www.ageuk 
.org.uk/Documents/EN-GB/For-professionals/Policy/healt h-and-wellbeing/report_bgs_frailty_language_and_perception s.pdf?dtrk=true. Accessed on 15 Jan 2020

6. Ambagtsheer RC, Archibald MM, Lawless M, Mills D, Yu S (2019) General practitioners 'perceptions, attitudes and experiences of frailty and frailty screening. Aust J Gen Pract 48(7):426-434

7. Archibald MM, Lawless M, Gill TK, Chehade MJ (2020) Orthopaedic surgeons' perceptions of frailty and frailty screening. BMC Geriatr 20(17):1-11

8. Nimmons D, Pattison T, O'Neill P (2018) Medical student attitudes and concepts of frailty and delirium. Eur Geriatr Med 9(1):45-50

9. McCarthy F, Winter R, Levett, (2020) An exploration of medical student attitudes towards older persons and frailty during undergraduate training. Eur Geriatr Med. https://doi.org/10.1007/s4199 9-020-00430-y

10. Windhaber T, Koula ML, Ntzani E, Velivasi A, Rizos E, Doumas MT (2018) Educational strategies to train health care professionals across the education continuum on the process of frailty prevention and frailty management: a systematic review. Aging Clin Exp Res 30(12):1409-1415

11. Avgerinou C, Kotsani M, Gavana M, Andreou M, Papageorgiou DI, Roka V (2020) Perceptions, attitudes and training needs of primary healthcare professionals in identifying and managing frailty: a qualitative study. Eur Geriatr Med. https://doi.org/10.1007/ s41999-020-00420-0

12. Arakawa Martins B, Jadczak AD, Dollard J, Barrie H, Mahajan N, Tam KL (2020) Fifth-year medical students' perceptions of the importance of frailty and competence in assessing, diagnosing and managing frailty before and after a geriatric medicine course. Australas J Ageing 39(3):e472-e477

13. Qualtrics. Provo. USA. 2019

14. British Geriatrics Society. Frailty: what's it all about? In: Good Practice Guide. British Geriatrics Society. 2018. https://www.bgs. org.uk/sites/default/files/content/resources/files/2018-05-23/Frail ty- what's it all about.pdf. Accessed 21 Nov 2019

15. British Geriatrics Society. Fit for Frailty Part 1: Consensus best practice guidance for the care of older people living in community and outpatient settings. 2017. http://www.bgs.org.uk/campaigns/ fff/fff_full.pdf. Accessed 21 Nov 2019

16. Gordon AL, Blundell AG, Gladman JRF, Masud T (2010) Are we teaching our students what they need to know about ageing? Results from the UK National Survey of Undergraduate Teaching in Ageing and Geriatric Medicine. Age Ageing 39(3):382-385

17. Gordon AL, Blundell A, Dhesi JK, Forrester-paton C, Forresterpaton J, Mitchell HK (2014) UK medical teaching about ageing is improving but there is still work to be done: The second national survey of undergraduate teaching in ageing and geriatric medicine. Age Ageing 43(2):293-297

18. Tullo ES, Gordon AL (2013) Teaching and learning about dementia in UK medical schools: a national survey. BMC Geriatr 13:1-6

19. Fisher J, Gordon A, MacLullich A, Tullo E, Davis DHJ, Blundell A (2015) Towards an understanding of why undergraduate teaching about delirium does not guarantee gold-standard practiceresults from a UK national survey. Age Ageing 44(1):166-170

20. Vaismoradi M, Turunen H, Bondas T (2013) Content analysis and thematic analysis: Implications for conducting a qualitative descriptive study. Nurs Heal Sci 15(3):398-405

21. Gordon A. The British Geriatrics Society Recommended Curriculum in Geriatric Medicine for Medical Undergraduates. British Geriatrics Society. 2013. https://www.bgs.org.uk/resources/thebgs-recommended-curriculum-in-geriatric-medicine-for-medic al-undergraduates. Accessed on 21 Nov 2019
22. Young $\mathbf{J}$ (2014) We must recognise frailty as a long term condition. https://www.england.nhs.uk/blog/john-young/. Accessed on 17 Sep 2019

23. Masud T, Blundell A, Gordon AL, Mulpeter K, Roller R, Singler K (2014) European undergraduate curriculum in geriatric medicine developed using an international modified Delphi technique. Age Ageing 43(5):695-702

24. Samra R, Cox T, Gordon AL, Conroy SP, Lucassen MFG, Griffiths A (2017) Factors related to medical students' and doctors' attitudes towards older patients: a systematic review. Age Ageing 46(6):911-919

25. Samra R, Griffiths A, Cox T, Conroy S, Gordon A, Gladman JRF (2015) Medical students' and doctors' attitudes towards older patients and their care in hospital settings: a conceptualisation. Age Ageing 44(5):776-783

26. Rockwood K, Song X, MacKnight C, Bergman H, Hogan D, McDowell I et al (2005) A global clinical measure of fitness and frailty in elderly people. CMAJ 173(5):489-495

27. Oswald A, Czupryn J, Wiseman J, Snell L (2014) Patient-centred education: what do students think? Med Educ 48(2):170-180

28. Hewitt J, Carter B, McCarthy K, Pearce L, Law J, Wilson FV (2019) Frailty predicts mortality in all emergency surgical admissions regardless of age. An observational study. Age Ageing 48(3):388-394

29. Martin GP, Sperrin M, Ludman PF, Debelder MA, Gunning M, Townend J (2018) Do frailty measures improve prediction of mortality and morbidity following transcatheter aortic valve implantation? An analysis of the UK TAVI registry. BMJ Open 8(6):1-9

30. Villani ER, Tummolo AM, Palmer K, Gravina EM, Vetrano DL, Bernabei R (2018) Frailty and atrial fibrillation: a systematic review. Eur J Intern Med 56:33-38

31. Athari F, Hillman KM, Frost SA (2019) The concept of frailty in intensive care. Aust Crit Care 32(2):175-178

32. Claramita M, Setiawati EP, Kristina TN, Emilia O, van der Vleuten C (2019) Community-based educational design for undergraduate medical education: a grounded theory study. BMC Med Educ 19(1):1-10

33. Waters-Dapre E, Moy L, Haskins M (2017) Community placements in foundation year 1: maximising potential. Age Ageing 46:i28-i30

34. Reeves D, Pye S, Ashcroft DM, Clegg A, Kontopantelis E, Blakeman $\mathrm{T}$ (2018) The challenge of ageing populations and patient frailty: can primary care adapt? BMJ 362:1-7

35. NHS England. Updated guidance on supporting routine frailty identification and frailty care through the GP Contract 2017/2018. 2017. ttps://www.england.nhs.uk/publication/supporting-routinefrailty-identification-and-frailty-through-the-gp-contract-20172 018/. Accessed 28 Mar 2020

36. Sockalingam S, Tan A, Hawa R, Pollex H, Abbey S, Hodges BD (2014) Interprofessional education for delirium care: a systematic review. J Interprof Care 28(4):345-351

37. Babine RL, Hyrkäs KE, Hallen S, Wierman HR, Bachand DA, Chapman JL et al (2018) Falls and delirium in an acute care setting: a retrospective chart review before and after an organisationwide interprofessional education. J Clin Nurs 27:e1429-e1441

38. Jackson M, Pelone F, Reeves S, Hassenkamp AM, Emery C, Titmarsh K (2016) Interprofessional education in the care of people diagnosed with dementia and their carers: a systematic review. BMJ Open 6(8):e010948

39. Biggs JB, Tang C (2011) Teaching for quality learning at university: what the student does, 4th edn. McGraw-Hill Education, Maidenhead

40. Wormald BW, Schoeman S, Somasunderam A, Penn M (2009) Assessment drives learning: an unavoidable truth? Anat Sci Educ 2(5):199-204 
41. Clegg A, Young J, Iliffe S, Olde Rikkert MGM, Rockwood K, Rikkert M (2013) Frailty in older people summary. Lancet 381:752-762

42. Cruz-Jentoft AJ, Bahat G, Bauer J, Boirie Y, Bruyère O, Cederholm T (2019) Sarcopenia: revised European consensus on definition and diagnosis. Age Ageing 48(1):16-31

43. Health Service Journal. Mrs Andrews' story-Her failed care pathway. 2016. https://www.youtube.com/watch?v=Fj_9HG_ TWEM. Accessed on 13 Sep 2019
Publisher's Note Springer Nature remains neutral with regard to jurisdictional claims in published maps and institutional affiliations. 